\title{
Nostalgia and Temporal Life Satisfaction
}

\author{
Shengquan Ye \\ Department of Applied Social Sciences, City University of Hong Kong \\ Ting Kin Ng \\ Department of Social Work and Social Administration, The University of Hong Kong \\ Chui Ling Lam \\ Department of Applied Social Sciences, City University of Hong Kong
}

Correspondence concerning this article should be sent to Shengquan Ye.

Address: Department of Applied Social Sciences, City University of Hong Kong, Tat Chee Avenue, Kowloon, Hong Kong

Tel: (852) 34428114

Fax: (852) 34420283

Email: sam.ye@ cityu.edu.hk 


\begin{abstract}
Recent research has shown that nostalgia, an apparently past-oriented emotion, may render the present self more positive and promote a brighter outlook on the future. The current study examined whether experimentally induced nostalgia would impact the levels of and associations among past, present, and future life satisfaction. Among 250 university students (86 males and 164 females, aged 16 to 26 years), nostalgia was manipulated through the recollection of nostalgic (vs. ordinary) events. In support of our hypotheses, the results showed that nostalgic experiences not only led to a larger contrast between past life satisfaction versus present and future life satisfaction, but also weaker associations between past and future life satisfaction and between present and future life satisfaction. Overall, the findings suggest that nostalgic experiences can render more distinct judgements on temporal life satisfaction.
\end{abstract}

Keywords: temporal life satisfaction; nostalgia; nostalgic experience 


\section{Introduction}

Unlike other creatures, human beings do not always think about what is going on at present (Killingsworth \& Gilbert, 2010). Apart from considering the present, people spend a considerable amount of time recollecting the past and anticipating the future (Cheung et al., 2013; Epstude \& Peetz, 2012). This ability to travel through time mentally is unique to human beings (Suddendorf \& Corballis, 2007). The capacity for mental time travel not only enables people to experience emotions such as regret, hope, and nostalgia (Epstude \& Peetz, 2012), but also allows people to evaluate their life satisfaction across different time frames (Pavot, Diener, \& Suh, 1998; Ye, 2007). The current study endeavors to examine how nostalgia, a sentimental longing for one's past (Sedikides, Wildschut, Arndt, \& Routledge, 2008; Wildschut, Sedikides, Arndt, \& Routledge, 2006), affects the levels of and associations among past, present, and future life satisfaction.

\section{Temporal Life Satisfaction}

Over the past few decades there has been a growing interest in the area of subjective well-being (Diener, 1984; Diener, Suh, Lucas, \& Smith, 1999; Ye, 2007). As the cognitive component of subjective well-being, life satisfaction refers to a person's global evaluation of the quality of his or her life (Diener et al., 1999). Some researchers have taken into consideration the effect of temporal focus on life satisfaction (Karniol \& Ross, 1996). Hagerty (2003) suggested that research on life satisfaction should pay more attention to what Lowenstein and Elster (1992) termed "intertemporal judgment", which refers to the paired comparisons between two time points, because this judgment can offer evidence on whether the life satisfaction of a particular group of individuals has increased, decreased, or remained constant. Hagerty (2003) meta-analyzed 71 studies on intertemporal judgment of life satisfaction. The results revealed that when individuals were asked how satisfied they were with their current lives compared to some past time, most reported that they were more 
satisfied now than in the past. However, the results also showed that when individuals were asked about life satisfaction of the average person, most perceived that the average person's life was more satisfying in the past than at present. The author suggested that these two inconsistent results might be due to several sources of bias such as cognitive processing heuristics, self-appraisal bias, and information bias in media news.

By adding a temporal dimension in the measure of life satisfaction, Pavot et al. (1998) distinguished among past, present, and future life satisfaction. The concept of temporal life satisfaction is especially useful in examining life satisfaction among people who have experienced or expect life changes that result in sharp contrasts of life satisfaction across temporal frames (Pavot et al., 1998; Ye, 2007). Previous research has shown that when people are asked to assess their past, present, and future life satisfaction, they generally consider that their present lives is more satisfying than their past lives, and anticipate that their future lives would be even more satisfying than their present lives (Busseri, 2013; Busseri, Choma, \& Sadava, 2009). This upward subjective trajectory has been observed in people in all ages except the very old adults (Busseri, 2013; Staudinger, Bluck, \& Herzberg, 2003). Busseri et al. (2009) found that not only optimists but also pessimists reported upward trajectories in life satisfaction from the past to the future.

\section{Nostalgia and the Past, Present, and Future}

Nostalgia has historically been considered as a neurological disease or a psychological disorder (Wildschut et al., 2006; Ye, Ngan, \& Hui, 2013). In the late $20^{\text {th }}$ century scholars has begun to reconceptualize nostalgia as a positive emotion (Davis, 1977; Wildschut et al., 2006), which is prevalent and is experienced virtually by everyone (Sedikides, Wildschut, Routledge, \& Arndt, 2015; Ye et al., 2013). Wildschut and colleagues (2006) found that the majority of university students reported experiencing nostalgia at least once a week. Hepper and colleagues (2014) found that nostalgia is conceptualized and experienced similarly across 
different cultures. When people experience nostalgia, they mostly think about close others or momentous life events, and the self is prominently featured as a protagonist (Hepper, Ritchie, Sedikides, \& Wildschut, 2012; Wildschut et al., 2006).

Nostalgia and the past. Scholars have postulated that nostalgia is a mixed or bittersweet emotion containing both positive and negative elements related to the past (Johnson-Laird \& Oatley, 1989; Werman, 1977; Wildschut et al., 2006). On one hand, nostalgic experience may be filled with "past beauty, pleasure, joy, satisfaction, goodness, happiness, love" (Davis, 1977, p. 14) and so forth. On the other hand, nostalgia may involve negative components such as sorrow or mourning about the past (Ortony, Clore, \& Collins, 1988), such as "hurts, annoyances, disappointments, and irritations" (Davis, 1977, p. 418). Werman (1977) contended that nostalgia involves "wistful pleasure, a joy tinged with sadness" (p. 393). In a content-analysis study, Wildschut et al. (2006) instructed undergraduate students to write narratives about an nostalgic experience and to describe how they felt about the experience. The results showed that nostalgia narratives included both positive and negative life events.

Nostalgia and the present. Although the content of nostalgia experiences may encompass a mixture of positive and negative elements about the past, research has generally documented that nostalgia is an important resource for present psychological health and well-being (Routledge, Wildschut, Sedikides, \& Juhl, 2013). McAdams and colleagues (McAdams, 2001; McAdams, Reynolds, Lewis, Patten, \& Bowman, 2001) identified two narrative patterns that a person adopt to give meaning and coherence to his or her life story. The first pattern is the contamination sequence, in which the narrative moves from a positive life scene to a negative one. The second pattern is the redemption sequence, in which the narrative progresses from a negative life scene to a positive or triumphant one. It was found that contamination sequences was associated with poor psychological well-being, while 
redemption sequences was related to good psychological well-being (McAdams et al., 2001). Wildschut et al. (2006) revealed that in nostalgia narratives, redemption sequences were more prevalent compared with contamination sequences. Therefore, even when nostalgic experiences contain negative events, they can still lead to positive outcomes (Routledge et al., 2013). Furthermore, Hepper et al. (2012) found that laypersons considered positive feelings such as happiness and fondness as more representative of nostalgia compare with negative feelings such as sadness and regret. Other studies have revealed that nostalgia enhances positive affect, increases positive self-regard, and promotes social connectedness, all of which are essential for maintaining optimal level of psychological health and well-being (Hepper et al., 2012; Routledge et al., 2013; Vess, Arndt, Routledge, Sedikides, \& Wildschut, 2012; Wildschut et al., 2006; Wildschut, Sedikides, Routledge, Arndt, \& Cordaro, 2010; Zhou, Sedikides, Wildschut, \& Gao, 2008).

Nostalgia and the future. While nostalgia is seemingly past-oriented (Wildschut et al., 2006), recent studies have suggested that it tends to shed a positive light on the future (Cheung, Sedikides, \& Wildschut, 2016; Cheung et al., 2013; Juhl, Routledge, Arndt, Sedikides, \& Wildschut, 2010; Routledge, Juhl, Abeyta, \& Roylance, 2014). Although mental time travel into the past and the future are interdependent cognitive processes (Klein, Robertson, \& Delton, 2010; Viard et al., 2011), people do not necessarily form realistic expectations based on real past events (Epstude \& Peetz, 2012). In particular, people may fantasize about favorable outcomes that may not come to pass (Taylor, Pham, Rivkin, \& Armor, 1998), and people's predictions about the future tend to be optimistically biased (Epstude \& Peetz, 2012). Since thinking about the past will make the temporal perspective more salient, it would be interesting to investigate how nostalgia may influence people's thoughts about the present and future.

According to terror management theory, individuals turn to meaning-providing 
structures to overcome the knowledge of future mortality (Greenberg \& Arndt, 2012). Past studies have shown that nostalgia bolsters a sense of meaning in life, as it brings to mind meaningful life events such as holidays and weddings (Routledge, Arndt, Sedikides, \& Wildschut, 2008; Routledge et al., 2011; Routledge et al., 2013; Routledge, Wildschut, Sedikides, Juhl, \& Arndt, 2012). As a meaning-providing resource, nostalgia serves the existential function that buffer the association between the awareness of the future mortality and death anxiety (Routledge et al., 2008; Routledge et al., 2014). Recent studies have shown that both trait nostalgia and experimentally induced state nostalgia alleviate the effect of mortality salience on death anxiety (Juhl et al., 2010; Routledge et al., 2008; Routledge et al., 2014).

Apart from mitigating existential threat, nostalgia may also boost optimism (Sedikides et al., 2008). Researchers have argued that if the present self can derive positivity from the past, such positivity can stretch out in time and promote a bright vision of the future (Cheung et al., 2016; Cheung et al., 2013; Davis, 1977; Routledge et al., 2014). Cheung et al. (2013) found that compared with ordinary narratives, nostalgic narratives encompassed a greater amount of optimistic expressions. They also found that participants recalling nostalgic events showed a higher level of optimism compared with their counterparts recalling ordinary events.

\section{The Current Study}

Recent research has suggested that nostalgia, an apparently past-oriented emotion, may render the present self more positive (Routledge et al., 2013; Wildschut et al., 2006) and contribute to a brighter outlook on the future (Cheung et al., 2016; Cheung et al., 2013; Routledge et al., 2014). Given the impact of nostalgia on temporal thought, it is surprising that past research has not examined how nostalgia affects people's evaluations of their past, present, and future lives. The current study aims to contribute to the literature by examining whether experimentally induced nostalgia would influence the levels of and associations 
among past, present, and future life satisfaction.

As aforementioned, prior research has revealed that people generally report an upward trajectory in temporal life satisfaction from the past to the present and future (Busseri, 2013; Busseri et al., 2009). In light of the research findings that nostalgia promotes psychological well-being (Hepper et al., 2012; Routledge et al., 2013; Vess et al., 2012; Wildschut et al., 2006; Wildschut et al., 2010; Zhou et al., 2008) and generates a positive view of the future (Cheung et al., 2016; Cheung et al., 2013; Juhl et al., 2010; Routledge et al., 2008; Routledge et al., 2014), it is expected that nostalgia would increase present and future life satisfaction, resulting in a larger contrast with past life satisfaction. Besides, past studies have shown that past, present, and future life satisfaction are moderately correlated with each other (Busseri et al., 2009; Ye, 2007). However, whether nostalgia would moderate the associations among past, present and future life satisfaction has not been examined previously. Given the contrast brought by nostalgic experience, it is anticipated that nostalgia would make the evaluations of past, present and future lives less related to each other, resulting in lower correlations among past, present, and future life satisfaction. The following two hypotheses are formulated:

H1: The difference between past life satisfaction versus present and future life satisfaction would be larger in the nostalgia condition than in the control condition.

H2: Induced nostalgia would moderate the associations among past, present, and future life satisfaction, such that the associations among past, present, and future life satisfaction would be weaker in the nostalgia condition than in the control condition.

\section{Method}

\section{Participants}

A total of 280 university students in Hong Kong were invited to participate in the study. Since prior studies have demonstrated that the nostalgia manipulation may have little or no impact for people who were less prone to nostalgia (e.g., Juhl et al., 2010; Routledge et al., 
2014), the participants were required to complete a measure of nostalgia proneness

(Southampton Nostalgia Scale; Routledge et al., 2008) and only those who scored higher than or equal to the scale midpoint on the scale were used in the subsequent analysis. As a result, 250 participants were obtained, whose ages ranged from 19 to 26 years $(M=21.93, S D=$ 1.35). Among them, 146 were in the nostalgia group (57 males and 89 females) and 104 in the control group (29 males and 75 females).

\section{Measures}

Temporal life satisfaction. The Chinese version of the 9-item Temporal Satisfaction With Life Scale (TSWLS) validated by Ye (2007) was used to measure past (e.g., "I am satisfied with my life in the past"), present (e.g., "The current conditions of my life are excellent"), and future life satisfaction (e.g., "I expect my future life will be ideal for me"). This instrument is a revised version of the original 15-item TSWLS developed by Pavot et al. (1998). Each subscale of life satisfaction is assessed with 3 parallel items. All items are rated on a 7-point Likert scale ranging from 1 (strongly disagree) to 7 (strongly agree). Higher scores reflect higher levels of temporal life satisfaction. The past, present, and future life satisfaction subscales showed good internal consistency reliability (Cronbach's $\alpha$ s $=.91, .89$, and .96 , respectively).

\section{Procedure}

This study applied the experimental procedure devised by Wildschut et al. (2006) to manipulate nostalgia. Participants completed a questionnaire containing the manipulation of nostalgia and dependent measures. In the nostalgia condition, participants received instructions prompting them to provide descriptions of the circumstances that triggered nostalgia and to write in detail about a nostalgic experience. In the control condition, participants were asked to write about ordinary events in the previous day. Participants in both conditions were then instructed to complete the TSWLS. All participants were assured 
that their responses were anonymous and confidential.

\section{Results}

\section{Content of Nostalgic Experience}

Prior to the testing of the hypotheses, we conducted a content analysis of the reported nostalgic experience. Previous studies have shown that nostalgic experience may consist of positive and negative events (Johnson-Laird \& Oatley, 1989; Werman, 1977; Wildschut et al., 2006). The positivity expressed in participants' nostalgic narratives was rated by three independent raters on a 7-point scale ranging from 1 (extremely negative) to 7 (extremely positive). Interrater reliability for the positivity ratings was satisfactory (Cronbach's $\alpha=.87$ ). The mean of positivity rating was slightly above the scale midpoint of $4.0(M=4.54, S D$ $=.96)$.

Moreover, the sequences of participants' nostalgic narratives were coded by three independent raters using the scheme developed by Wildschut et al. (2006). Specifically, the raters were instructed to judge whether a narrative was characterized by a redemption sequence, a contamination sequence, or neither. Interrater reliability was assessed using Krippendorff's $\alpha$, which can be used with any number of raters and levels of measurement (Hayes \& Krippendorff, 2007). An adequate interrater reliability was obtained (Krippendorff's $\alpha=.72$ ). As expected, redemption sequences (55\%) were more prevalent than contamination sequences $(10 \%)$, and $35 \%$ of the narratives followed neither sequence. The results were consistent with Wildschut et al. (2006), which found that nostalgic narratives more often followed a redemption sequence than a contamination sequence.

\section{Mean Differences in Temporal Life Satisfaction}

Table 1 shows the means, standard deviations, correlations and reliabilities among the three temporal life satisfaction subscales by group. A $3 \times 2$ two-way mixed analysis of variance (ANOVA) was performed as an initial analysis of the effects of nostalgia and 
temporal perspective on life satisfaction. The dependent variable was the level of life satisfaction. The within-subjects factor was temporal perspective (past, present, and future). The between-subjects factor was group (nostalgia vs. control). It was found that there was a significant main effect of temporal perspective, $F(2,496)=3.79, p=.023, \eta^{2}=.02$. Post hoc comparisons with Dunn-Sidak correction revealed that future life satisfaction was significantly higher than past life satisfaction $(p=.004)$. The difference between past and present life satisfaction and that between present and future life satisfaction were not significant. The main effect of group, $F(1,248)=.09, p=.769, \eta^{2}=.00$ and the temporal perspective $\times$ group interaction effect, $F(2,496)=.81, p=.446, \eta^{2}=.00$, were not significant. Three planned contrasts were conducted to test the differences in the three temporal life satisfaction subscales between the nostalgia and control conditions. No significant difference was found in past life satisfaction, $t(248)=0.52, p=.303, \eta^{2}=.00$, present life satisfaction, $t(248)=.49, p=.313, \eta^{2}=.00$, and future life satisfaction, $t(248)=.78, p=.219, \eta^{2}=.00$.

Insert Table 1 about here

According to $\mathrm{H} 1$, nostalgia would enlarge the difference between past life satisfaction versus present and future life satisfaction. To test this hypothesis, a planned interaction contrast was conducted to test whether the difference between past life satisfaction versus present and future life satisfaction was greater in the nostalgia condition compared with the control condition. The results of the planned interaction contrast revealed that, as expected, the difference between past life satisfaction versus present and future life satisfaction was marginally significantly greater in the nostalgia condition than in the control condition, $t(248)$ $=1.44, p=.076, \eta^{2}=.01$. To take a closer examination of this specific interaction effect (see Figure 1), two planned contrasts were conducted within each condition. Consistent with our 
hypothesis, in nostalgia condition, past life satisfaction was significantly lower in contrast with present and future life satisfaction, $t(248)=3.18, p<.001, \eta^{2}=.04$, whereas no significant difference was found in control condition, $t(248)=.80, p=.211, \eta^{2}=.00$.

Insert Figure 1 about here

\section{Associations among Past, Present, and Future Life Satisfaction}

It was predicted that nostalgia would moderate the associations among past, present, and future life satisfaction. A multi-group confirmatory factor analysis (CFA) was conducted using LISREL 8.80 (Jöreskog \& Sörbom, 2006) to examine the factor correlations invariance across the nostalgia and control conditions. Prior to the CFA, multivariate normality tests were performed using PRELIS (Jöreskog \& Sörbom, 1999) and the results suggested that the assumption of multivariate normality was violated in both the nostalgia and control conditions. Therefore, asymptotic covariance matrices (ACMs) were calculated and robust maximum likelihood (RML) estimation rather than maximum likelihood (ML) was used. By using this estimation method, Satorra-Bentler scaled chi-square statistics (Satorra \& Bentler, 1994) were computed. A number of fit indices were considered to evaluate the goodness-of-fit of the models, including root mean square error of approximation (RMSEA; Steiger, 1990), standardized root mean residual (SRMR; Bentler, 1995), comparative fit index (CFI; Bentler, 1990), non-normed fit index (NNFI; Tucker \& Lewis, 1973). Following the recommendation by $\mathrm{Hu}$ and Bentler (1999), a good model fit is indicated by RMSEA < .06, $\mathrm{SRMR}<.08, \mathrm{CFI}>.95$, and NNFI $>.95$. Nested model comparisons were performed using Crawford and Henry's (2003) computer program, which implements the method of comparing Satorra-Bentler scaled chi-square suggested by Satorra and Bentler (2001).

Prior to the multi-group CFA, two sets of single group CFAs of the hypothesized 
three-factor model were performed separately for the nostalgia condition and the control condition. An overall assessment of the goodness-of-fit indices suggested that the model fit was adequate for the nostalgia condition, $\chi_{\mathrm{sb}}^{2}(24, N=146)=30.81, p=.159$, $\mathrm{RMSEA}=.044$ $(90 \% \mathrm{CI}=.000$ to .085$), \mathrm{SRMR}=.032, \mathrm{CFI}=1.00, \mathrm{NNFI}=.99$, and the control condition, $\chi_{\mathrm{sb}}^{2}(24, N=104)=36.89, p=.045, \mathrm{RMSEA}=.072(90 \% \mathrm{CI}=.011$ to .116$), \mathrm{SRMR}=.049$, $\mathrm{CFI}=.99, \mathrm{NNFI}=.98$.

Multi-group CFA involves a set of hierarchical steps (Cheung \& Rensvold, 2002). Table 2 summarizes the fit statistics for the models testing invariance across the nostalgia and control conditions. To establish configural invariance, an unconstrained factor model was estimated across the two conditions simultaneously. A good model fit was obtained, $\chi_{\mathrm{sb}}^{2}(48, N$ $=250)=67.26, p=.035, \mathrm{RMSEA}=.057(90 \% \mathrm{CI}=.016$ to .087$), \mathrm{SRMR}=.040, \mathrm{CFI}=.99$, $\mathrm{NNFI}=.99$, indicating that the factor structure was equivalent across the two conditions. This model was used as the baseline model for the subsequent tests of invariance.

Insert Table 2 about here

To test metric invariance (Gregorich, 2006), the factor loadings were constrained to be equal across the two conditions. The model fit was not significantly worsened, $\Delta \chi_{\text {scaled }}^{2}(6, N=$ $250)=8.53, p=.202$, indicating that the factor loadings were invariant across the two conditions. Moreover, further imposing equality constraints of the factor variances across the two conditions did not result in a significant decline of the model fit, $\Delta \chi_{\text {scaled }}^{2}(3, N=250)=$ $1.06, p=.786$, showing invariance of factor variances.

In order to test the hypothesized differences in the associations among temporal life satisfaction subscales between the nostalgia and control conditions, further equality constraints on factor covariances were imposed one by one. As expected, constraining the 
covariance between present and future life satisfaction to be equal across the two conditions significantly worsened the model fit, $\Delta \chi_{\text {scaled }}^{2}(1, N=250)=4.90, p=.027$, indicating that the association between present and future life satisfaction was different between the two conditions. Similarly, constraining the covariance between past and future life satisfaction to be equal across the two conditions resulted in a marginally significant drop in the model fit, $\Delta \chi_{\text {scaled }}^{2}(1, N=250)=3.29, p=.070$, suggesting that the association between past and future life satisfaction differ between the two conditions. However, constraining the covariance between past and present life satisfaction to be equal across the two conditions did not lead to a significant change in the model fit, $\Delta \chi_{\text {scaled }}^{2}(1, N=250)=.95, p=.330$. The association between past and present life satisfaction did not differ across the two conditions.

Additionally, to assess strong factorial invariance (Gregorich, 2006), the items intercepts were constrained to be equal across the two conditions. The fit of the model did not decrease significantly, $\Delta \chi_{\text {scaled }}^{2}(6, N=250)=10.30, p=.112$, indicating that the item intercepts were invariance across the two conditions. Subsequently, the factor means were constrained to be equal across the two conditions. The model fit did not deteriorate significantly, $\Delta \chi_{\text {scaled }}^{2}(3, N=$ $250)=1.19, p=.755$, suggesting that the factor means did not differ between the two conditions.

Furthermore, to examine strict factorial invariance (Gregorich, 2006), equality constraints of measurement errors across the two groups were further imposed. The model did not significantly decrease the model fit, $\Delta \chi_{\text {scaled }}^{2}(9, N=250)=5.76, p=.764$, demonstrating measurement error invariance. The final model fitted the data well, $\chi_{\mathrm{sb}}^{2}(76, N$ $=250)=92.96, p=.091, \mathrm{RMSEA}=.042(90 \% \mathrm{CI}=.000$ to .070$), \mathrm{SRMR}=.063, \mathrm{CFI}=.99$, NNFI $=.99$. Coefficients of the final model are shown in Figure 2. 
In sum, results from the multi-group CFA were consistent with our predictions. While most parameters in the models were invariant across the two groups, the correlation between past and future life satisfaction was significantly lower in the nostalgia condition $(r=.28, p$ $<.05)$ than in the control condition $(r=.47, p<.001)$. Besides, the correlation between present and future life satisfaction was also lower in the nostalgia condition $(r=.49, p<.001)$ than in the control condition $(r=.66, p<.001)$. Both findings provided clear support for the moderating effect of nostalgia on the associations among temporal life satisfaction.

\section{Discussion}

By drawing together the theories and empirical findings on temporal life satisfaction (Busseri, 2013; Busseri et al., 2009; Pavot et al., 1998; Ye, 2007) and nostalgia (Cheung \& Rensvold, 2002; Cheung et al., 2016; Routledge et al., 2014; Routledge et al., 2013;

Wildschut et al., 2006), this study advances the existing literature by illuminating the impacts of manipulated nostalgia on the differences and associations among past, present, and future life satisfaction. To the best of our knowledge, this study is the first to link nostalgia to temporal life satisfaction. The current findings provide good support that nostalgia enlarges the difference between past life satisfaction versus present and future life satisfaction and partial support for the moderating effect of nostalgia on the associations among the three temporal life satisfaction subscales.

The content analysis reveals that participants' nostalgic narratives show a medium level of positivity, reflecting that their nostalgic narratives contains similar amounts of positive and negative events. This finding is consistent with the nostalgia literature suggesting that nostalgia involve both positive and negative elements (Johnson-Laird \& Oatley, 1989; Werman, 1977; Wildschut et al., 2006). Similar to the study by Wildschut et al. (2006), the present study shows that nostalgic narratives follow redemption sequences more often 
compared with contamination sequences. Overall, it is replicated that nostalgic narratives tend to lead to a positive evaluation, even though there is a mixture of positive and negative elements.

The results of this study indicate that the difference between past life satisfaction versus present and future life satisfaction was stronger in the nostalgia condition than in the control condition. Past studies on temporal life satisfaction have documented that when people are asked to evaluate their past, present, and future life satisfaction, they tend to perceive that their future lives and present lives are more satisfying than their past lives, exhibiting an upward subjective trajectory (Busseri, 2013; Busseri et al., 2009). The current results indicate that this upward subjective trajectory in temporal life satisfaction is more prominent when people recall nostalgic events than when they recall ordinary events. These findings may be explained by the notion that nostalgic experiences are typically characterized by redemption sequence, in which negative experiences result in a positive outcomes (Routledge et al., 2013; Wildschut et al., 2006).

The current results demonstrate that manipulated nostalgia moderated the association between past and future life satisfaction and that between present and future life satisfaction. As predicted, future life satisfaction was less strongly associated with past and present life satisfaction in the nostalgia condition than in the control condition. Thinking about the past may make the temporal frames more salient and therefore may render the perceptions of past, present and future lives more distinct from each other. However, this study shows that manipulated nostalgia does not weaken the relationship between past life satisfaction and present life satisfaction. One possible explanation is that while the evaluation of the future life is based on imaginations and predictions that are often inaccurate (Epstude \& Peetz, 2012; Taylor et al., 1998), the evaluation of the past and present life is based on real life experiences, which may not be easily manipulated through experimental procedure. Hence, the correlation 
between past and present life satisfaction tends to be robust across different conditions.

The present study has several implications for the existing literature. First, the current findings contribute to the research on intertemporal judgment of life satisfaction. Previous studies on intertemporal judgment have indicated that people tend to consider their current lives as more satisfying than their past lives (Hagerty, 2003). Moreover, past studies on temporal life satisfaction have demonstrated an upward subjective trajectory in the ratings of temporal life satisfaction, in which the lives at present are perceived as more satisfying than the past, and the lives in the future are anticipated to be even more satisfying than the present (Busseri, 2013; Busseri et al., 2009). While the effect of nostalgia on the subjective trajectory in temporal life satisfaction ratings has not been investigated previously, the findings of this study show that experimentally induced nostalgia may lead to a clearer distinction in intertemporal judgement and increase the difference between past life satisfaction versus present and future life satisfaction, resulting in a steeper subjective trajectory.

Second, the present findings also enrich the current understanding of nostalgia. The literature has documented that nostalgia is a mixed or bittersweet emotion involving both positive and negative elements about the past (Johnson-Laird \& Oatley, 1989; Werman, 1977; Wildschut et al., 2006). Moreover, nostalgia has been found to promote better psychological well-being (Hepper et al., 2012; Routledge et al., 2013; Vess et al., 2012; Wildschut et al., 2006; Wildschut et al., 2010; Zhou et al., 2008). Furthermore, recent studies have revealed that nostalgia mitigates the threat of future mortality (Juhl et al., 2010; Routledge et al., 2008; Routledge et al., 2014) and enhances optimism (Cheung et al., 2016; Cheung et al., 2013). However, the extent to which nostalgia influences the associations among past, present, and future life satisfaction has not been examined. Findings from the present study have showed that nostalgia does not only affect the mean levels, but also the structural associations, of temporal life satisfaction. In a similar vein, it would be plausible that the relationships of 
temporal life satisfaction with relevant factors that were examined before (e.g., demographic variables, dispositional traits, attitudes, and behaviors, etc.) may be moderated by nostalgic experience. Such findings, if any, will contribute to a more comprehensive understanding about the effect of nostalgia on psychological well-being.

In spite of the contributions, the current study has its limitations that need to be noted in future research. First, this study only investigated a sample of undergraduate students. Research on temporal life satisfaction has suggested that age may affect the evaluation of past, present, and future lives (Busseri, 2013; Staudinger, Bluck, \& Herzberg, 2003). For instance, Busseri (2013) revealed an inclining trajectory in temporal life satisfaction among young adults but an declining trajectory among older adults. In addition, age may also affect nostalgia. Sedikides et al. (2008) argued that due to bereavement and declines in physical functioning, older adults may experience nostalgia more frequently and nostalgia would play a more prominent role in renewing a symbolic connection with close others. Future research is recommended to examine how nostalgia influences temporal life satisfaction in other age groups. Second, this study did not examine the impact of trait nostalgia (i.e., nostalgia proneness), but used it as a screening tool before the experiments. Some recent studies have shown that trait nostalgia proneness may moderate the effect of experimentally induced nostalgia (Cheung et al., 2016; Routledge et al., 2014). For example, Cheung et al. (2016) found that induced nostalgia fostered optimism only among participants with high trait nostalgia but not among their counterparts with low trait nostalgia. Further studies may investigate whether trait nostalgia would moderate the effect of manipulated nostalgia on temporal life satisfaction. 


\section{References}

Bentler, P. M. (1990). Comparative fit indexes in structural models. Psychological Bulletin, 107(2), 238-246.

Bentler, P. M. (1995). EQS Structural Equations Program Manual. Encino, CA: Multivariate Software.

Busseri, M. A. (2013). How dispositional optimists and pessimists evaluate their past, present and anticipated future life satisfaction: A lifespan approach. European Journal of Personality, 27(2), 185-199.

Busseri, M. A., Choma, B. L., \& Sadava, S. W. (2009). "As good as it gets" or "The best is yet to come"? How optimists and pessimists view their past, present, and anticipated future life. Personality and Individual Differences, 47(4), 352-356.

Cheung, G. W., \& Rensvold, R. B. (2002). Evaluating goodness-of-fit indexes for testing measurement invariance. Structural Equation Modeling, 9(2), 233-255.

Cheung, W.-Y., Sedikides, C., \& Wildschut, T. (2016). Induced nostalgia increases optimism (via social-connectedness and self-esteem) among individuals high, but not low, in trait nostalgia. Personality and Individual Differences, 90, 283-288.

Cheung, W.-Y., Wildschut, T., Sedikides, C., Hepper, E. G., Arndt, J., \& Vingerhoets, A. J. J. M. (2013). Back to the future: Nostalgia increases optimism. Personality and Social Psychology Bulletin, 39(11), 1484-1496.

Crawford, J. R., \& Henry, J. D. (2003). The Depression Anxiety Stress Scales (DASS): Normative data and latent structure in a large non-clinical sample. British Journal of Clinical Psychology, 42(2), 111-131.

Davis, F. (1977). Nostalgia, identity, and the current nostalgia wave. Journal of Popular Culture, 11, 414-425.

Diener, E. (1984). Subjective well-being. Psychological Bulletin, 95(3), 542-575. 
Diener, E., Suh, E. M., Lucas, R. E., \& Smith, H. L. (1999). Subjective well-being: Three decades of progress. Psychological Bulletin, 125(2), 276-302.

Epstude, K., \& Peetz, J. (2012). Mental time travel: A conceptual overview of social psychological perspectives on a fundamental human capacity. European Journal of Social Psychology, 42(3), 269-275.

Greenberg, J., \& Arndt, J. (2012). Chapter: Terror management theory. In Handbook of theories of social psychology (Vol 1) (pp. 398-415). Thousand Oaks, CA: Sage Publications Ltd.

Gregorich, S. E. (2006). Do self-repoty instruments allow meaningful comparisons across diverse population groups? Testing measurement invariance using the confirmatory factor analysis framework. Medical Care, 44(11 Suppl 3), S78-S94.

Hagerty, M. R. (2003). Was life better in the "good old days"? Intertemporal judgments of life satisfaction. Journal of Happiness Studies, 4(2), 115-139.

Hayes, A. F., \& Krippendorff, K. (2007). Answering the call for a standard reliability measure for coding data. Communication Methods and Measures, 1, 77-89.

Hepper, E. G., Ritchie, T. D., Sedikides, C., \& Wildschut, T. (2012). Odyssey's end: Lay conceptions of nostalgia reflect its original homeric meaning. Emotion, 12(1), 102-119.

Hepper, E. G., Wildschut, T., Sedikides, C., Ritchie, T. D., Yung, Y.-F., Hansen, N., et al. (2014). Pancultural nostalgia: Prototypical conceptions across cultures. Emotion, 14(4), $733-747$.

Hu, L.-t., \& Bentler, P. M. (1999). Cutoff criteria for fit indexes in covariance structure analysis: Conventional criteria versus new alternatives. Structural Equation Modeling, $6(1), 1-55$.

Johnson-Laird, P. N., \& Oatley, K. (1989). The language of emotions: An analysis of a 
semantic field. Cognition and Emotion, 3(2), 81-123.

Jöreskog, K. G., \& Sörbom, D. (1999). PRELIS 2: User's reference guide. Lincolnwood, IL: Scientific Software International.

Jöreskog, K. G., \& Sörbom, D. (2006). LISREL 8.80. Chicago, IL: Scientific Software International.

Juhl, J., Routledge, C., Arndt, J., Sedikides, C., \& Wildschut, T. (2010). Fighting the future with the past: Nostalgia buffers existential threat. Journal of Research in Personality, 44(3), 309-314.

Karniol, R., \& Ross, M. (1996). The motivational impact of temporal focus: Thinking about the future and the past. Annual Review of Psychology, 47, 593-620.

Killingsworth, M. A., \& Gilbert, D. T. (2010). A wandering mind is an unhappy mind. Science 330, 932.

Klein, S. B., Robertson, T. E., \& Delton, A. W. (2010). Facing the future: Memory as an evolved system for planning future acts. Memory \& Cognition, 38(1), 13-22.

Loewenstein, G., \& Elster, J. (1992). Choice over time. New York: Russell Sage Foundation.

McAdams, D. P. (2001). The psychology of life stories. Review of General Psychology, 5(2), 100-122.

McAdams, D. P., Reynolds, J., Lewis, M., Patten, A. H., \& Bowman, P. J. (2001). When bad things turn good and good things turn bad: Sequences of redemption and contamination in life narrative and their relation to psychosocial adaptation in midlife adults and in students. Personality and Social Psychology Bulletin, 27(4), 474-485.

Ortony, A., Clore, G. L., \& Collins, A. (1988). The cognitive structure of emotions. Cambridge England ; New York: Cambridge University Press.

Pavot, W., Diener, E., \& Suh, E. (1998). The Temporal Satisfaction With Life Scale. Journal of Personality Assessment, 70(2), 340-354. 
Routledge, C., Arndt, J., Sedikides, C., \& Wildschut, T. (2008). A blast from the past: The terror management function of nostalgia. Journal of Experimental Social Psychology, 44(1), 132-140.

Routledge, C., Arndt, J., Wildschut, T., Sedikides, C., Hart, C. M., Juhl, J., et al. (2011). The past makes the present meaningful: Nostalgia as an existential resource. Journal of Personality and Social Psychology, 101(3), 638-652.

Routledge, C., Juhl, J., Abeyta, A., \& Roylance, C. (2014). Using the past to promote a peaceful future: Nostalgia proneness mitigates existential threat induced nationalistic self-sacrifice. Social Psychology, 45(5), 339-346.

Routledge, C., Wildschut, T., Sedikides, C., \& Juhl, J. (2013). Nostalgia as a resource for psychological health and well-being. Social and Personality Psychology Compass, $7(11), 808-818$.

Routledge, C., Wildschut, T., Sedikides, C., Juhl, J., \& Arndt, J. (2012). The power of the past: Nostalgia as a meaning-making resource. Memory, 20(5), 452-460.

Satorra, A., \& Bentler, P. M. (1994). Corrections to test statistics and standard errors in covariance structure analysis. In A. Von Eye \& C. C. Clogg (Eds.), Latent variable analysis: Applications for developmental research (pp. 399-419). Thousand Oaks, CA: Sage.

Satorra, A., \& Bentler, P. M. (2001). A scaled difference chi-square test statistic for moment structure analysis. Psychometrika, 66(4), 507-514.

Sedikides, C., Wildschut, T., Arndt, J., \& Routledge, C. (2008). Nostalgia: Past, present, and future. Current Directions in Psychological Science, 17(5), 304-307.

Sedikides, C., Wildschut, T., Routledge, C., \& Arndt, J. (2015). Nostalgia counteracts self-discontinuity and restores self-continuity. European Journal of Social Psychology, 45(1), 52-61. 
Staudinger, U. M., Bluck, S., \& Herzberg, P. Y. (2003). Looking back and looking ahead: Adult age differences in consistency of diachronous ratings of subjective well-being. Psychology and Aging, 18(1), 13-24.

Steiger, J. H. (1990). Structural model evaluation and modification: An interval estimation approach. Multivariate Behavioral Research, 25(2), 173-180.

Suddendorf, T., \& Corballis, M. C. (2007). The evolution of foresight: What is mental time travel, and is it unique to humans. Behavioral and Brain Sciences, 30(3), 299-313.

Taylor, S. E., Pham, L. B., Rivkin, I. D., \& Armor, D. A. (1998). Harnessing the imagination: Mental simulation, self-regulation, and coping. American Psychologist, 53(4), 429-439.

Tucker, L. R., \& Lewis, C. (1973). A reliability coefficient for maximum likelihood factor analysis. Psychometrika, 38(1), 1-10.

Vess, M., Arndt, J., Routledge, C., Sedikides, C., \& Wildschut, T. (2012). Nostalgia as a resource for the self. Self and Identity, 11(3), 273-284.

Viard, A., Chetelat, G., Lebreton, K., Desgranges, B., Landeau, B., de La Sayette, V., et al. (2011). Mental time travel into the past and the future in healthy aged adults: An fMRI study. Brain and Cognition, 75(1), 1-9.

Werman, D. S. (1977). Normal and pathological nostalgia. Journal of the American Psychoanalytic Association, 25(2), 387-398.

Wildschut, T., Sedikides, C., Arndt, J., \& Routledge, C. (2006). Nostalgia: Content, Triggers, Functions. Journal of Personality and Social Psychology, 91(5), 975-993.

Wildschut, T., Sedikides, C., Routledge, C., Arndt, J., \& Cordaro, F. (2010). Nostalgia as a repository of social connectedness: The role of attachment-related avoidance. Journal of Personality and Social Psychology, 98(4), 573-586.

Ye, S. (2007). Validation of the Temporal Satisfaction With Life Scale in a sample of Chinese 
university students. Social Indicators Research, 80(3), 617-628.

Ye, S., Ngan, R. Y. L., \& Hui, A. N. N. (2013). The state, not the trait, of nostalgia increases creativity. Creativity Research Journal, 25(3), 317-323.

Zhou, X., Sedikides, C., Wildschut, T., \& Gao, D.-G. (2008). Counteracting loneliness: On the restorative function of nostalgia. Psychological Science, 19(10), 1023-1029. 
Table 1

Means, Standard Deviations, Correlations and Reliabilities among Past, Present, and Future Life Satisfaction by Group $(N=250)$

\begin{tabular}{|c|c|c|c|c|c|}
\hline Variable & $M$ & $S D$ & 1 & 2 & 3 \\
\hline \multicolumn{6}{|c|}{ Nostalgia condition $(n=146)$} \\
\hline 1. Past LS & 13.72 & 3.63 & $(.92)$ & & \\
\hline 2. Present LS & 14.25 & 3.87 & $.52 * * *$ & $(.91)$ & \\
\hline 3. Future LS & 14.63 & 3.16 & $.26 * * *$ & $.47 * * *$ & $(.95)$ \\
\hline \multicolumn{6}{|c|}{ Control condition $(n=104)$} \\
\hline 1. Past LS & 13.95 & 3.33 & $(.89)$ & & \\
\hline 2. Present LS & 14.02 & 3.54 & $.53 * * *$ & $(.86)$ & \\
\hline 3. Future LS & 14.32 & 3.11 & $.44 * * *$ & $.61 * * *$ & $(.96)$ \\
\hline \multicolumn{6}{|l|}{ Total $(N=250)$} \\
\hline 1. Past LS & 13.82 & 3.50 & $(.91)$ & & \\
\hline 2. Present LS & 14.16 & 3.73 & $.53 * * *$ & $(.89)$ & \\
\hline 3. Future LS & 14.50 & 3.14 & $.33 * * *$ & $.52 * * *$ & $(.96)$ \\
\hline
\end{tabular}

Note. $\mathrm{LS}=$ Life Satisfaction. ${ }^{* * *} p<.001$. 
Table 2

Summary of the Fit Indices for the Models Testing Invariance across the Nostalgia and Control Conditions $(N=250)$

\begin{tabular}{|c|c|c|c|c|c|c|c|}
\hline \multicolumn{2}{|r|}{ Model } & $\chi_{\mathrm{sb}}^{2}$ & $d f$ & RMSEA $[90 \% \mathrm{CI}]$ & SRMR & CFI & NNFI \\
\hline 3. & Model $2+$ equal factor variances & $77.68^{*}$ & 57 & $.054[.015, .082]$ & .073 & .99 & .99 \\
\hline 5 . & Model 3 + equal covariance between past LS and future LS & $80.41 *$ & 58 & $.056[.020, .083]$ & .071 & .99 & .99 \\
\hline 6. & Model 3 + equal covariance between past LS and present LS & $78.63^{*}$ & 58 & $.054[.014, .082]$ & .066 & .99 & .99 \\
\hline 7. & Model $6+$ equal intercepts & $88.25^{*}$ & 64 & $.055[.021, .082]$ & .066 & .99 & .99 \\
\hline
\end{tabular}

Note. $\mathrm{LS}=$ Life satisfaction. $* p<.05$. 


\section{Total Score}

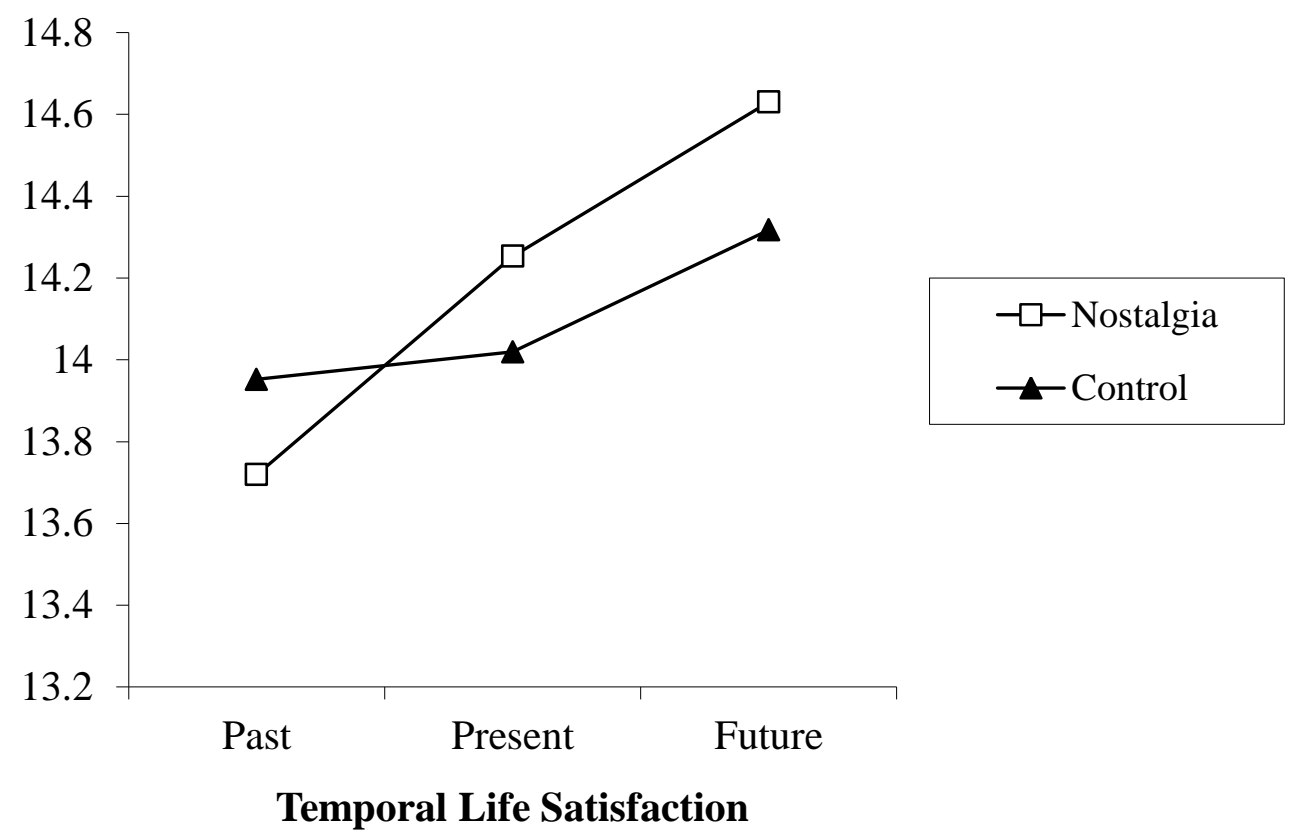

Figure 1. Means of temporal life satisfaction across the nostalgia and control conditions $(N=$ 250). 


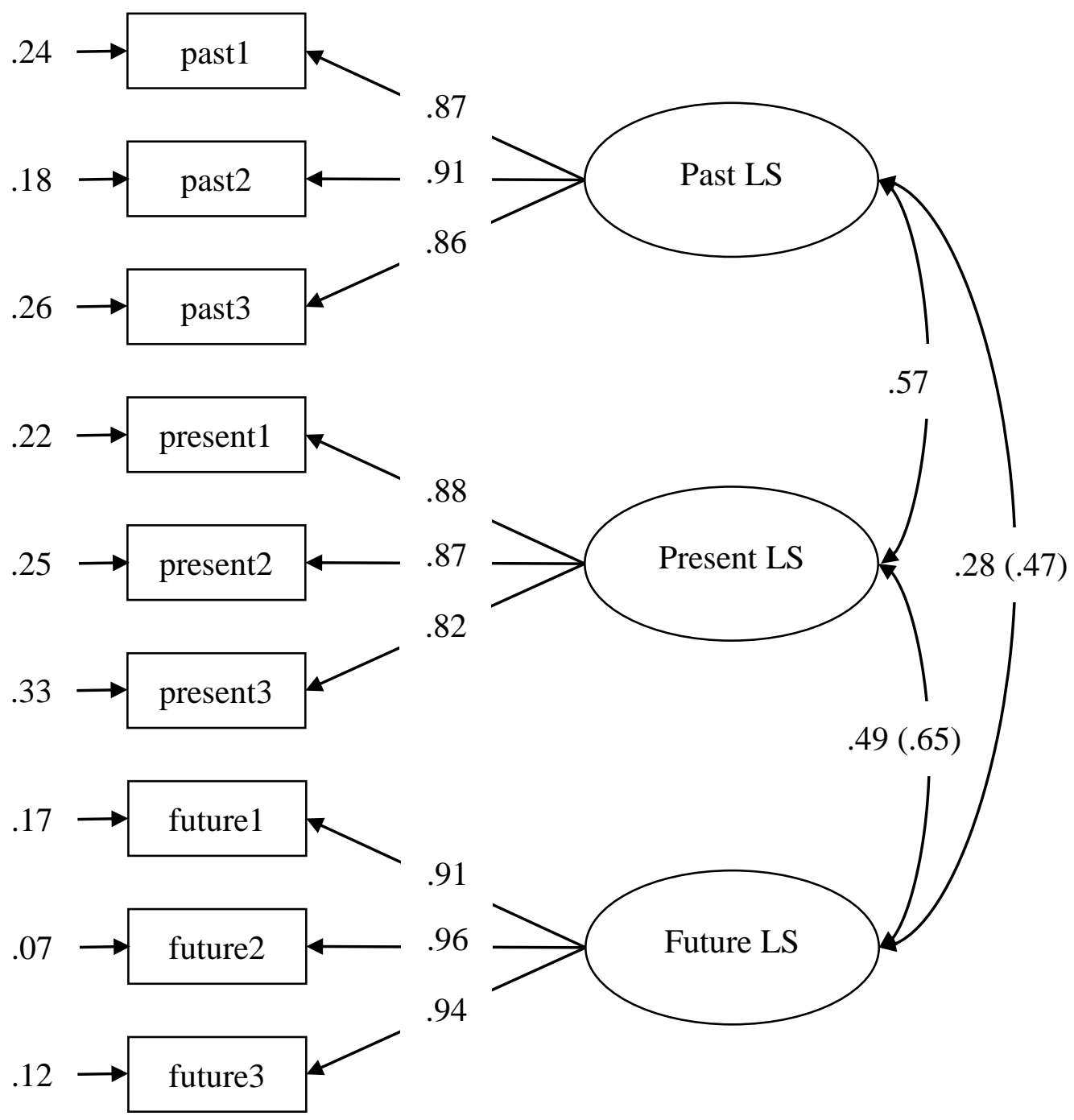

Figure 2. Multi-group confirmatory factor analysis of the Temporal Satisfaction With Life Scale across the nostalgia and control conditions $(N=250)$. Standardized coefficients are presented. Values in parentheses are coefficients for the control condition. All coefficients were significant at $p<.05$ level. LS $=$ Life satisfaction. 